Int. J. Med. Surg. Sci,

1(1):5-11, 2014.

\title{
The Number of Nephrons in the Kidney: A Relevant Question Implicated with Arterial Hypertension
}

\author{
El Número de Nefronas en el Riñón: Una Interrogante \\ Relevante Implicada con la Hipertensión Arterial
}

\author{
Carlos Alberto Mandarim-de-Lacerda*,*; Marcia Barbosa Aguila* \& Mauricio Younes-Ibrahim**
}

MANDARIM-DE-LACERDA, C. A.; AGUILA, M. A. \& YOUNES-IBRAHIM, M. The number of nephrons in the kidney: a relevant question implicated with arterial hypertension. Int. J. Med. Surg. Sci., 1(1):5-11, 2014.

SUMMARY: Stereological methods are used to obtain quantitative information about the three-dimensional structures based on observations on cutting planes or, to a limited degree, projections. Stereological methods, which are used in biological research, and especially in the study of normal and pathological kidney, are powerful tools for the study of the kidney. The study of kidney development, with emphasis on subtypes of clusters found in this period of intrauterine life, has relevance to assess renal maturity and the consequences of changes in the normal process. Several studies have shown that the total number of nephrons varies widely in normal human kidneys. An association between the small number of nephrons and subsequent development of hypertension in adulthood has increasingly been accepted. There is sufficient experimental and clinical evidence to conclude that blood pressure is associated with the number of nephrons, although this concept is not unanimous in the literature.

KEY WORDS: Stereological methods; Quantitative information; Kidney; Number of nephrons; Hypertension.

\section{INTRODUCTION}

There is increasing evidence that primary hypertension, coronary heart disease, and other aspects of so-called metabolic syndrome that develop in adulthood are prepared in fetal or early postnatal life, hence this phenomenon also known as prenatal or fetal programming (Amann et al., 2004).

Stereological methods are used to obtain quantitative information about the three-dimensional structures based on observations on cutting planes or, to a limited degree, projections. Stereological methods, which are used in biological research, and especially in the study of normal and pathological kidney, are powerful tools for the study of the kidney (Nyengaard, 1999; Bertram, 2001; Mandarim-de-Lacerda, 2003)

\section{MATERIAL AND METHOD}

To estimate the number of clusters (or nephrons) the kidney must be properly prepared. Currently we do design-based stereology, and the method of choice is the socalled "fractionator-disector" (Cullen-McEwen et al., 2011, 2012).

\footnotetext{
* Laboratório de Morfometria, Metabolismo e Doença Cardiovascular, Centro Biomédico, Instituto de Biologia, Universidade do Estado do Rio de Janeiro, Rio de Janeiro, Brasil.

** Laboratório de Nefrologia, Departamento de Medicina Interna, Faculdade de Ciências Médicas. Universidade do Estado do Rio de Janeiro, Rio de Janeiro, Brasil.
} 
For example, with an animal model (mouse), the kidney should be removed (the right kidney, for example) and cleaned from the surrounding fat. The kidney should be cut longitudinally and fixed in freshly prepared fixative (1.27 Mol/L formaldehyde $0.1 \mathrm{M}$ phosphate buffer, $\mathrm{pH} 7.2$ ) for $48 \mathrm{~h}$ at room temperature. Subsequently, the two halves of the kidney should be embedded with the cutting face down in embedding media.

The block should be sectioned into a series of $10 \mu \mathrm{m}$ thick, and sections should be stained with hematoxylin and eosin, and mounted on glass slides. In a successive series of sections, beginning with a random section, several disector pairs may be constructed with an interval of $20 \mu \mathrm{m}$ (d), which represents roughly $1 / 3$ to $1 / 4$ of the glomerular average diameter in the mouse (previously defined). From there, a disector pair should be selected considering every tenth section from the first section randomly chosen, and the second section from the tenth section (physical disector). Briefly, in each disector pair similar digital image may be obtained in both section areas (consider anatomical landmarks on sections to be sure of the similar areas). Then, two identical laptops can be used (with 14-inch screen, for example) where the two images are visualized and analyzed simultaneously, the first picture on the first computer and the second image on the second computer. In both laptops, the test area is placed over the pictures in order to exactly compare the same structures (AT, for example, produced with the online software Stepanizer (www.stepanizer.com)) (Tschanz et al., 2011).

We should count glomerular profiles that appear in the first image (left computer, here considered the upper plane of the disector or "look-up"), but not in the subsequent plan (right computer herein considered the lower plane of the disector or "look -down"). Also, glomeruli should not be counted when they touch the "forbidden line" or its extensions (incorporated in AT) (Gundersen, 1977).

The numerical density of glomeruli in the right kidney ( $\mathrm{Nv}$ [glom]) will be estimated as $\mathrm{Nv}$ [glom] = SQ- $/ \mathrm{d} \sum A T$ where Q- is the number of glomerular profiles counted with the disector, $\mathrm{d}$ is the distance between the "disector pair".
The total number of glomeruli of the right kidney ( $\mathrm{N}$ [glom]) will be estimated as $\mathrm{N}$ [glom] $=(1 /$ f1) $\sum(1 / \mathrm{f} 2) \sum$ SQ-considering $\mathrm{f} 1$ and $\mathrm{f} 2$ as sampling fractions (samples of kidney and the areas of the sections of the sample) (Brown et al., 2002).

The plan considered "look-up" may be analyzed again, now with a test system with 49 points (PT) produced with Stepanizer. The volume density of glomeruli ( $\mathrm{Vv}$ [glom]) will be estimated using the technique of "point counting", where: $\mathrm{Vv}$ [glom] $=\mathrm{P}$ [glom] / PT, P [glom] is the number of points overlying the glomeruli. The average volume of the glomeruli is estimated by the ratio of $\mathrm{Vv}$ [glom] / Nv [glom] (Nyengaard, 1999).

Another set of sections, may be stained with periodic acid-Schiff (PAS, to highlight basement membrane of glomerular capillaries, tubular epithelium, and Bowman's capsule). These sections may be evaluated to rate "sclerotic glomeruli" (those that have Bowman's capsule rupture or collapse of capillary loops with a scar anywhere in the glomerulus). Thus, the ratio of sclerotic / non-sclerotic glomeruli can be estimated, as a percentage, in a sample of at least ten fields of the renal cortex in each kidney. Counts should be made within a test area obtained with Stepanizer program, as already indicated (Mandarim-de-Lacerda et al., 2010).

\section{DISCUSSION}

For over 25 years Barry M. Brenner postulated that the reduction in the number of nephrons is the renal abnormality that contributes to arterial hypertension in the general population (Brenner et al., 1988; Brenner, 1994). This concept was reinforced by the observation that the retardation of renal development, as occurs in individuals with low body mass at birth, gives rise to increased postnatal risks for arterial hypertension as well as increased risk for kidney disease.

This hypothesis is based on observations that indicate (Brenner; Mackenzie \& Brenner, 1995; Luyckx \& Brenner, 2005): 
1) a direct relationship between body mass at birth and the number of nephrons,

2) an inverse relationship between body mass at birth and hypertension later life, and

3) an inverse relationship between the number of nephrons and blood pressure, regardless of whether the reduced number of nephrons congenitally or post-natal life.

An association between the small number of nephrons and subsequent development of hypertension in adulthood has increasingly been accepted. The underlying pathological mechanisms are unknown. The smaller number of nephrons is associated with marked changes in the glomerular structures that comprise the remaining glomeruli, in particular smaller capillary supply, reduction of podocyte density and thickening of the glomerular basement membrane (GBM), which may predispose to early glomerular sclerosis (Hostetter et al., 2001). This has been demonstrated experimentally in the offspring of mothers fed a low-protein diet (Villar-Martini et al., 2009).

Several studies have shown that the total number of nephrons varies widely in normal human kidneys. Whereas studies agree that the average number of nephrons is about 900 thousand to 1 million per kidney, the numbers for individual kidney vary from about 200,000 to more than 2.5 million nephrons (Bertram et al., 2011). In addition, the aging process leads to a loss of glomeruli due to glomerulosclerosis (Baylis \& Corman, 1998; Bercovich, 2002).

The study of kidney development, with emphasis on subtypes of clusters found in this period of intrauterine life, has relevance to assess renal maturity and the consequences of changes in the normal process. An example is the study of the development of colon forms, $\mathrm{S}$ forms, and vascular glomeruli in human fetal period (Almeida \& Mandarim-de-Lacerda, 2002; Almeida et al., 2003).

The glomeruli vary between individuals and are dependent on blood pressure, diseases that affect the kidneys and other health attributes, but most of the variation in the number of nephrons is present at birth and therefore is determined by the development (Cullen-McEwen et al., 2011).

The number of nephrons in normal human kidneys may vary by up to eight times (Merlet-Benichou et al., 1999). Consequently, a significant part of the population may be in a situation of risk for the onset of hypertension. For example, the study of the number of nephrons in 15 children of three months of age observed that the number of nephrons varied between approximately 250,000 to 1.1 million. Given that new nephrons are usually not produced in human kidneys after about 36 weeks of pregnancy, it is important to examine renal function in individuals born with relatively low number of nephrons. Several studies have reported a direct correlation between body mass at birth and the number of nephrons, and an indirect association between the number of nephrons and blood pressure. Associations between low body mass at birth and cardiovascular diseases, including hypertension, have been widely reported (Bertram et al.; Rookmaaker \& Joles, 2013).

Reductions in the area of glomerular filtration have been associated with the onset of hypertension. The number of nephrons is significantly greater in normotensive WistarKyoto (WK) rats compared to spontaneously hypertensive rats (SHR), but no difference in the glomerular filtration area between these groups of mice. This suggests that it is not a corollary of the direct correlation between the number of nephrons, or area of glomerular filtration, and the level of blood pressure in this rat model (Black et al., 2004). However, this concept is not unanimous as a study described SHR with a lower number of nephrons, in comparison to WK rats, resulting in a reduced total glomerular volume in adult SHR (Skov et al., 1994).

In addition, the loss of one allele for glial cell line-derived neurotrophic factor (growth derived neurotrophic factor or GDNF) results in $30 \%$ less glomeruli in normal young rats. This allows an interesting study of glomerular filtration rate in GDNF heterozygous animals, which have a reduced number of innate 
nephrons. In these animals, there is deterioration in renal structure and function and increased blood pressure in adulthood. With aging, mice heterozygous GDNF maintains glomerular filtration rate (GFR) and renal blood flow normal, despite the reduced number of nephrons. The elevation of blood pressure, glomerular hypertrophy and hyperfiltration in GDNF heterozygous animals may indicate a compensatory mechanism by which GFR is maintained even in the presence of a reduced number of nephrons (CullenMcEwen et al., 2003).

An interesting question is linked with the deficit in the number of nephrons that may explain why some racial groups have a higher incidence of hypertension and renal disease than other groups (Kett \& Bertram, 2004). This issue is relevant in countries with a significant population mix, as is the case of Brazil and the United States.

In the southeastern United States, African-Americans have an estimated incidence of hypertension and end-stage kidney disease that is five times greater than that observed in the white population. African-Americans also have a higher frequency of small body mass at birth and high incidence of arterial hypertension. This suggests a possible correlation between these two factors, likely due to reduced number of nephrons that fail to develop in the kidney of the AfricanAmerican population. However, no racial differences in the number and size of glomeruli were observed when the white population was compared with the African-American population, although the body mass at birth has been a determining factor in the number of glomeruli in adulthood (Hughson et al., 2003).

Impaired fetal growth with subsequent rapid postnatal growth are associated with the programming of hypertension and the appearance of elements called "metabolic syndrome" in adulthood. This was evaluated in a model of intrauterine growth restriction (IUGR) in mini-pigs. The number of nephrons was positively correlated with body mass at birth and negatively correlated with blood pressure. Pigs IUGR have fewer nephrons and increased blood pressure in adulthood (Myrie et al., 2011).

The various diseases that have been associated with glomerular hyperfiltration, either per nephron or per total kidney, include diabetes mellitus, polycystic kidney disease, secondary focal segmental glomerulosclerosis caused by a reduction in renal mass, sickle cell anemia, high altitude renal syndrome and obesity. The remnant nephrons in a kidney with nephron deficiency are submitted to glomerular hyperfiltration and its consequences, such as hypertension, proteinuria, glomerulosclerosis, and end-stage renal disease requiring hemodialysis (Brenner et al., 1996). However, some authors consider that the evidence supporting the hypothesis that hyperfiltration after prenatal programming are still circumstantial. A prerequisite for the establishment of this association in future studies of long-term monitoring, would be the possibility of estimating glomerular numbers in living humans, further advancement in noninvasive techniques of investigation for which it is necessary (Schreuder \& Nauta, 2007).

One of the most relevant studies in humans, which tested the hypothesis that the decrease in the number of nephrons is one of the factors that contribute to the development of primary hypertension, used the stereological The method compared two populations of white European individuals (to remove the factor race or ethnic group), hypertensive and normotensive individuals. The study compared the number and the volume of glomeruli in 10 middle-aged subjects (age range 35-59 years) with a history of primary hypertension or left ventricular hypertrophy (or both), and lesions in the renal arterioles, with 10 normotensive subjects matched for sex, age, height and weight. All 20 subjects died in accidents. Those who had arterial hypertension had significantly fewer glomeruli per kidney than the matched normotensive controls (median, 702,379 glomeruli against 1,429,200 glomeruli). Individuals with hypertension also had a significantly higher glomerular volume than the controls, but few sclerotic glomeruli. Thus, the data supports the hypothesis that the number of nephrons is reduced in subjects with primary arterial hypertension (Keller et al., 2003). 
Protein restriction in maternal diet in rodents, or calorie restriction in maternal diet leads to hypertension in adult animals (Almeida and Mandarim-de-Lacerda, 2005a, 2005b). Rat offspring of mothers with normal levels of protein in the diet (19\% protein) or low protein content ( $5 \%$ of protein) were studied at $0,10,90$ and 180 days of age. The developing cortical structure showed immature glomeruli (forms in comma and Sshaped), and mature glomeruli at different rates. On day 10 (end of the glomerulogenesis period in rodents), immature corpuscles were observed only in the offspring of mothers with protein restriction, who had higher blood pressure and showed thickened GBM with deletion of the pedicles and the absence of the slit diaphragm with some podocytes adhered directly to the MBG and absent pedicles in adulthood. There were significantly fewer glomeruli developed in the offspring of mothers with protein restriction than in the offspring of mothers with normal protein (Villar-Martini et al.). Interestingly, moderate maternal protein restriction does not reduce the number of nephrons in the female offspring, but only in male offspring. The intrarenal renin-angiotensin system during development may play a key role in this protective effect seen in females (Woods et al., 2005).

Another issue that is increasingly present in studies linking nutrition and kidney refers to maternal vitamin $D$ deficiency and the appearance of an increased number of nephrons in the offspring (Maka et al., 2008). There is a high prevalence of vitamin $D$ insufficiency in women of reproductive age. We studied the first two generations of offspring (F1 and F2) of mice of mothers fed a standard diet or a diet deficient in vitamin D. In adulthood, the first two generations of mothers deficient in vitamin D showed high blood pressure and an increase in renal expression of renin and angiotensin II AT1 receptor. Both $\mathrm{F} 1$ and $\mathrm{F} 2$ generations of the group of vitamin $D$ deficient mothers had more immature glomeruli than offspring of control mothers. At 6 months of age, the F1 offspring of mothers with vitamin $D$ deficiency had more glomeruli than the $\mathrm{F} 1$ offspring from control mothers. Despite having the greatest number of glomeruli, the F1 offspring of mothers with vitamin $D$ deficiency had reduced expression of podocina and the increase in urinary urea and creatinine. These results demonstrate that maternal vitamin D deficiency accompanying changes in renal expression of important factors that may delay the maturation of glomeruli, extending the period of glomerulogenesis, which would lead to a greater number of glomeruli in postnatal life, but with functional impairment (Nascimento et al., 2012).

\section{CONCLUSIONS}

There is sufficient experimental and clinical evidence to conclude that blood pressure is associated with the number of nephrons, although this concept is not unanimous in the literature. More than that, it is observed that the "fetal programming" with maternal protein restriction programs to fewer nephrons in the offspring with sexual dimorphism, with females less sensitive than males in rodents. Besides the lower number of nephrons in the offspring, there is glomerular ultrastructural alteration correlated with the alterations in renal function in programming offspring. However, if maternal protein restriction leads to a reduction in the number of nephrons in the offspring, the maternal vitamin $D$ deficiency leads to an increase in the number of nephrons in the offspring, possibly by increasing the time duration of glomerulogenesis. However, it is still uncertain what the increased number of nephrons in the offspring might mean in the long term and more research is needed to understand this experimental finding.

\section{ACKNOWLEDGEMENTS}

CAML and MBA are supported as Researchers of the National Council for Technology and Research Development of Brazil (CNPq), and are qualified Scientists of the State of Rio de Janeiro of the Foundation of Rio de Janeiro for Research (FAPERJ). 
MANDARIM-DE-LACERDA, C. A.; AGUILA, M. A. \& YOUNES-IBRAHIM, M. El número de nefronas en el riñón: Una interrogante relevante implicada con la hipertensión arterial. Int. J. Med. Surg. Sci., 1(1):5-11, 2014.

RESUMEN: Métodos estereológicos se utilizan para obtener información cuantitativa acerca de las estructuras tridimensionales basados en observaciones sobre los planos de corte o en un grado limitado, sus proyecciones. Estos métodos que se utilizan en la investigación biológica y especialmente en el estudio de riñón normal y patológico son herramientas poderosas para el estudio renal. El estudio del desarrollo de los riñones, con énfasis en los subtipos de grupos celulares que se encuentran en esta etapa de la vida intrauterina, tiene relevancia para evaluar la madurez renal y las consecuencias de los cambios en el proceso normal. Varios estudios han demostrado que el número total de nefronas varía ampliamente en los riñones humanos normales. Una asociación entre el bajo número de nefronas y el posterior desarrollo de la hipertensión en la edad adulta, han sido cada vez más aceptado. Existe evidencia experimental y clínica suficiente para concluir que la presión arterial se asocia con el número de nefronas, aunque este concepto no es unánime en la literatura.

\section{PALABRAS CLAVE: Métodos estereológicos; Información cuantitativa; Riñón; Número de nefronas; Hipertensión.}

\section{REFERENCES}

Almeida, J. R. \& Mandarim-de-Lacerda, C. A. Quantitative study of the comma-shaped body, S-shaped body and vascularized glomerulus in the second and third human gestational trimesters. Early Hum. Dev., 69(1-2):1-13, 2002.

Almeida, J. R. \& Mandarim-de-Lacerda, C. A. Maternal gestational protein-calorie restriction decreases the number of glomeruli and causes glomerular hypertrophy in adult hypertensive rats. Am. J. Obstet. Gynecol., 192(3):945-51, 2005a.

Almeida, J. R. \& Mandarim-de-Lacerda, C. A . Overweight is gender-dependent in prenatal protein--calorie restricted adult rats acting on the blood pressure and the adverse cardiac remodeling. Life Sci., 77(12):1307-18, 2005b.

Almeida, J. R.; Passos, M. A. ; Souza, E. R. \& MandarimDe-Lacerda, C. A. Glomerular developmental chronology in human fetuses. J. Cell. Mol. Med., 7(4):492-3, 2003.

Amann, K.; Plank, C. \& Dotsch, J. Low nephron number-a new cardiovascular risk factor in children? Pediatr. Nephrol., 19(12):1319-23, 2004.

Baylis, C. \& Corman, B. The aging kidney: insights from experimental studies. J. Am. Soc. Nephrol., 9(4):699709, 1998.

Bercovich, E. A new target for urology: aging and renal function. Urol. Int., 69(2):91-4, 2002.

Bertram, J. F. Counting in the kidney. Kidney Int., 59(2): 792-6, 2001.
Bertram, J. F.; Douglas-Denton, R. N.; Diouf, B.; Hughson, M. D. \& Hoy, W. E. Human nephron number: implications for health and disease. Pediatr. Nephrol., 26(9):1529-33, 2011.

Black, M. J.; Briscoe, T. A.; Constantinou, M.; Kett, M. M. \& Bertram, J. F. Is there an association between level of adult blood pressure and nephron number or renal filtration surface area? Kidney Int., 65(2):582-8, 2004.

Brenner, B. M. The etiology of adult hypertension and progressive renal injury: an hypothesis. Bull. Mem. Acad. R. Med. Belg., 149(1-2):121-5; discussion 57, 1994.

Brenner, B. M.; Garcia, D. L. \& Anderson, S. Glomeruli and blood pressure. Less of one, more the other? Am. J. Hypertens., 1(4 Pt. 1):335-47, 1988.

Brenner, B. M.; Lawler, E. V. \& Mackenzie, H. S. The hyperfiltration theory: a paradigm shift in nephrology. Kidney Int., 49(6):1774-7, 1996.

Brown, J.; Briscoe, T. A.; Harding, R.; Cock, M. L.; Bertram, J. F: \& Black, J. M. Glomerular number and capillary dimensions in the normal lamb kidney. Image Anal. Stereol., 21:157-64, 2002.

Cullen-McEwen, L. A.; Armitage, J. A.; Nyengaard, J. R.; Moritz, K. M. \& Bertram, J. F. A design-based method for estimating glomerular number in the developing kidney. Am. J. Physiol. Renal Physiol., 300(6):F1448-53, 2011.

Cullen-McEwen, L. A. ; Douglas-Denton, R. N. \& Bertram, 
J. F. Estimating total nephron number in the adult kidney using the physical disector/fractionator combination. Methods Mol. Biol., 886: 333-50, 2012.

Cullen-McEwen, L. A.; Kett, M. M.; Dowling, J.; Anderson, W. P. \& Bertram, J. F. Nephron number, renal function, and arterial pressure in aged GDNF heterozygous mice. Hypertension, 41(2):335-40, 2003.

Gundersen, H. J. G. Notes on the estimation of the numerical density of arbitrary profiles: the edge effect. J. Microsc., 111:219-27, 1977.

Hostetter, T. H.; Olson, J. L.; Rennke, H. G.; Venkatachalam, M. A. \& Brenner, B. M. Hyperfiltration in remnant nephrons: a potentially adverse response to renal ablation. J. Am. Soc. Nephrol., 12(6):1315$25,2001$.

Hughson, M.; Farris, A. B. 3rd; Douglas-Denton, R.; Hoy, W. E. \& Bertram, J. F. Glomerular number and size in autopsy kidneys: the relationship to birth weight. Kidney Int., 63(6):2113-22, 2003.

Keller, G.; Zimmer, G.; Mall, G.; Ritz, E. \& Amann, K. Nephron number in patients with primary hypertension. N. Engl. J. Med., 348(2):101-8, 2003.

Kett, M. M. \& Bertram, J. F. Nephron endowment and blood pressure: what do we really know? Curr. Hypertens. Rep., 6(2):133-9, 2004.

Luyckx, V. A. \& Brenner, B. M. Low birth weight, nephron number, and kidney disease. Kidney Int. Suppl., (97):S68-77, 2005

Mackenzie, H. S. \& Brenner, B. M. Fewer nephrons at birth: a missing link in the etiology of essential hypertension? Am. J. Kidney Dis., 26(1):91-8, 1995.

Maka, N.; Makrakis, J.; Parkington, H. C.; Tare, M.; Morley, R. \& Black, M. J. Vitamin D deficiency during pregnancy and lactation stimulates nephrogenesis in rat offspring. Pediatr. Nephrol., 23(1):55-61, 2008.

Mandarim-de-Lacerda, C. A. Stereological tools in biomedical research. An. Acad. Bras. Cienc., 75(4):469-86, 2003.

Mandarim-de-Lacerda, C. A.; Santos, C. F. \& Aguila, M. $B$. Image analysis and quantitative morphology. Methods Mol. Biol., 611:211-25, 2010.

Merlet-Bénichou, C.; Gilbert, T.; Vilar, J.; Moreau, E.; Freund, N. \& Lelievre-Pegorier, M. Nephron number: variability is the rule. Causes and consequences. $L a b$. Invest., 79(5):515-27, 1999.

Myrie, S. B.; McKnight, L. L.; Van Vliet, B. N. \& Bertolo, R. F. Low birth weight is associated with reduced nephron number and increased blood pressure in adulthood in a novel spontaneous intrauterine growth-restricted model in Yucatan miniature Swine. Neonatology, 100(4):380-6, 2011.

Nascimento, F. A.; Ceciliano, T. C.; Aguila, M. B. \& Mandarim-de-Lacerda, C. A. Maternal vitamin D deficiency delays glomerular maturity in F1 and F2 offspring. PLoS One, 7(8):e41740, 2012.

Nyengaard, J. R. Stereologic methods and their application in kidney research. J. Am. Soc. Nephrol., 10(5):1100-23, 1999.

Rookmaaker, M. B. \& Joles, J. A. The nephron number counts-from womb to tomb. Nephrol. Dial. Transplant., 28(6):1325-8, 2013.

Schreuder, M. F. \& Nauta, J. Prenatal programming of nephron number and blood pressure. Kidney Int., 72(3):265-8, 2007.

Skov, K.; Nyengaard, J. R.; Korsgaard, N. \& Mulvany, M. J. Number and size of renal glomeruli in spontaneously hypertensive rats. J. Hypertens., 12(12):1373-6, 1994.

Tschanz, S. A.; Burri, P. H. \& Weibel, E. R. A simple tool for stereological assessment of digital images: the STEPanizer. J. Microsc., 243(1):47-59, 2011.

Villar-Martini, V. C.; Carvalho, J. J.; Neves, M. F.; Aguila, M. B. \& Mandarim-de-Lacerda, C. A. Hypertension and kidney alterations in rat offspring from low protein pregnancies. J. Hypertens., 27(Suppl. 6):S47-51, 2009.

Woods, L. L.; Ingelfinger, J. R. \& Rasch, R. Modest maternal protein restriction fails to program adult hypertension in female rats. Am. J. Physiol. Regul. Integr. Comp. Physiol., 289(4):R1131-6, 2005.

Correspondence to:

Prof. Dr. Carlos Alberto Mandarim de-Lacerda

Full Professor and Head of the Department of Anatomy State University of Rio de Janeiro

Av. 28 de Setembro 87 fds

P.O.Box 20551-030

Rio de Janeiro

BRAZIL

Phone $(+55.21)$ 2868-8316

FAX: 2868-8033

Email address: mandarim@uerj.br

URL: www.Immc.uerj.br

Received: $10-12-2013$

Accepted: 21-12-2013 